\title{
Erratum to: Tamlana nanhaiensis sp. nov., isolated from surface seawater collected from the South China Sea
}

\author{
Xiupian Liu • Qiliang Lai · Yaping Du • \\ Guangyu Li $\cdot$ Fengqin Sun $\cdot$ Zongze Shao
}

Published online: 22 July 2015

(C) Springer International Publishing Switzerland 2015

Erratum to: Antonie van Leeuwenhoek (2015) 107:1189-1196

DOI 10.1007/s10482-015-0410-x

In the original publication of the article, In Figure 1, Supplementary Figure S1 and Supplementary
Figure S2, the Genbank accession number for the 16S rRNA sequence of Tamlana nanhaiensis $\mathrm{FHC16}{ }^{\mathrm{T}}$ is incorrectly published as KC755038. The correct Genbank accession number should read as KF188783.

The online version of the original article can be found under doi:10.1007/s10482-015-0410-x.

X. Liu · Q. Lai · Y. Du · G. Li · F. Sun · Z. Shao $(\bowtie)$ State Key Laboratory Breeding Base of Marine Genetic Resources, Key Laboratory of Marine Biogenetic Resources, Third Institute of Oceanography, SOA, Key Laboratory of Marine Genetic Resources of Fujian Province, Xiamen 361005, China

e-mail: shaozz@163.com 